\title{
Análise Crítica do Discurso e Teorias Culturais: Hibridismo Necessário
}

\author{
(Critical Discourse Analysis and Cultural Theory:
}

Towards a Much Needed Hybridity)

\author{
Adriana Pagano \\ (Universidade Federal de Minas Gerais) \\ Célia Magalhães \\ (Universidade Federal de Minas Gerais)
}

\begin{abstract}
This paper invites theoretical reflection on critical discourse analysis (Chouliaraki e Fairclough, 1999), cultural studies and postcolonial studies as sites of bybridity of complementary knowledges which inform studies of the role of language in the representations of hybrid cultural identities. A theoretical dialogue is proposed between Bakbtin's concept of textual bybridization - borrowed by critical discourse analysis as a fundamental notion in textual interpretation and expanded so as to account for genres pertaining to emerging discourses -, and Homi Bhabha's concept of cultural hybridity, also drawing on Bakbtin in order to explain ambivalence in postcolonial cultures. An analysis of the poem "Para ouvir e entender 'Estrela'", by black Brazilian writer Cuti, is carried out in order to illustrate the potentiality of this theoretical dialogue for investigating cultural manifestations that seek to interrogate a concept and value system built on the basis of the denial of racial differences and their problematic insertion within the political and cultural territory of the nation.
\end{abstract}

KEY-WORDs: Textual and cultural hybridity; Postcolonialism; Critical discourse analysis.

RESUMO: Este artigo apresenta uma reflexão teórica sobre a análise de discurso crítica (Chouliaraki e Fairclough, 1999) e os estudos culturais e pós-coloniais, como espaços híbridos de saberes complementares que informam os estudos do papel da linguagem nas representações de identidades culturais híbridas. Propõe-se uma articulação do conceito bakbtiniano de hibridização textual-adotado na análise crítica do discurso como peça 
fundamental da prática de interpretação textual e expandido para dar conta de gêneros de discursos emergentes -, com o conceito de hibridismo cultural de Homi Bhabha (1998), uma reelaboração também do conceito de Bakbtin que visa dar conta do espaço pós-colonial ambivalente das culturas. Uma análise do poema "Para ouvir e entender 'Estrela'", do escritor brasileiro negro Cuti, é apresentada para ilustrar o potencial dessa articulação teórica para investigar manifestações culturais que buscam interrogar um sistema de valores e conceitos em torno da obliteração das diferenças raciais e sua inserção no espaço político e cultural da nação.

PaLAVRas-CHaVe: Hibridismo textual e cultural; Pós-colonialism; Análise de discurso crítica.

A filosofia mestiça ama os corpos misturados. Michel Serres, Filosofia Mestiça

\section{Espaços teóricos híbridos}

Algumas representações muito significativas informam o discurso de lingüistas contemporâneos em suas reflexões sobre a transdisciplinaridade na Lingüística Aplicada hoje. Duas delas em particular chamam nossa atenção e suscitam uma série de reflexões sobre o estatuto dessa disciplina e o lugar do lingüista aplicado no novo mapa conceitual com que nos deparamos no espaço pós-discursivo dos estudos lingüísticos. Trata-se de metáforas que sinalizam estados e comportamentos e geram leituras políticas das posturas acadêmicas. A primeira, a metáfora do nomadismo (Faure apud Celani 1998) aponta para o movimento e a mudança, gestos que provocam a desestabilização do lingüista aplicado, uma vez que novos espaços demandam novas teorias e conceitos com os quais o teórico precisa interagir. O nomadismo, contudo, implica no trânsito necessário entre as disciplinas, como forma de ampliação do olhar que lançamos ao nosso objeto de estudo; implica também numa certa indisciplina, como bem observou Moita Lopes (1998), e que entendemos no seu duplo sentido de ruptura das convenções da disciplina e dos limites dos espaços disciplinares. O nomadismo coloca o lingüista aplicado num reinado sem reino (Faure apud Moita Lopes, 1998 e Celani, 1998), segunda metáfora nesta discussão, que revela a vulnerabilidade e a contingência do suposto poder a que todo teórico aspira. Ser nômade transdiciplinar é estar continuamente desterrado, sem 
reino, porém assumindo um reinado intermitente, baseado no domínio, mesmo que parcial e fragmentado, de diferentes teorias vinculadas a diferentes tradições. Implica, pois, em adotar, no dizer de Serres (1993), uma filosofia mestiça na abordagem do objeto de estudo, a partir dos limiares críticos de espaços aparentemente diversos.

A noção de mestiçagem, ou mistura impura, remete à questão do hibridismo cultural, própria do mundo pós-colonial, em que as diferentes culturas constituem, através da migração e da sua condição de nomadismo, espaços transnacionais e transculturais de negociação. O hibridismo cultural se manifesta, dentre outras formas, na produção textual cada vez mais híbrida, a qual se constitui como o espaço adequado para a pluralidade de sentidos. No campo dos estudos de lingüística aplicada, a análise crítica do discurso (Chouliaraki e Fairclough 1999), em diálogo recente com os estudos pós-coloniais e os estudos culturais, se propõe enquanto espaço teórico transdisciplinar para a abordagem de gêneros de discursos híbridos, focalizando-se a análise intertextual como forma de articulação entre a análise textual e a análise sociocultural da produção e consumo dos textos.

Nossa proposta, neste trabalho, contempla uma reflexão teórica sobre a análise crítica do discurso e os estudos culturais e pós-coloniais, como espaços híbridos de saberes complementares que informam os estudos do papel da linguagem nas representações de identidades culturais híbridas. O foco é uma proposta de articulação do conceito bakhtiniano de hibridização textual, adotado na análise crítica do discurso como peça fundamental da prática de interpretação textual e expandido para dar conta de gêneros de discursos diversos, com o conceito de hibridismo cultural de Homi Bhabha (1998), usado para dar conta do espaço pós-colonial ambivalente das culturas. Iniciaremos com um breve percurso teórico pelos estudos culturais e pós-coloniais, passando, à análise crítica do discurso e à possibilidade de articulação dos conceitos de hibridismo textual e cultural. Finalizaremos com um exercício de análise, informada pela articulação teórica abordada, de um gênero do discurso literário, tomado aqui como um dos exemplos em que a experiência transcultural - neste caso de brasileiros afro-descendentes - se representa deliberadamente através do hibridismo textual. 


\section{Os estudos culturais e os estudos pós-coloniais}

A noção de hibridismo, segundo During (1999), pode ser entendida como processo de combinação dos produtos culturais com elementos novos para produzir efeitos diferentes em situações diferentes, como um dos conceitos chave para os estudos culturais. Juntamente com outros conceitos, essa noção informa as investigações culturais, cuja preocupação principal é com as representações que fazem, dos produtos culturais, os grupos de menor poder, especialmente na articulação de sua identidade. Tais investigações da cultura contemporânea serão engajadas, pois feitas a partir de perspectivas contra hegemônicas, visando à produção do conhecimento e à recepção de vozes marginalizadas pela cultura dominante.

A abordagem discursiva dos estudos culturais pressupõe uma noção de representação, de acordo com Hall (1997:61), enquanto “(...) processo pelo qual os membros de uma cultura usam a linguagem (definida amplamente como (...) qualquer sistema de significação) para produzir sentido”. Segundo o autor, tal noção pressupõe a aceitação de um certo grau de relativismo cultural entre as culturas, uma certa falta de equivalência e a necessidade de tradução do universo conceitual de uma cultura para outra.

O pós-colonialismo, conforme definição de Robinson (1997:121), é

um estado de cultura ou de estudos culturais, emergente do colonialismo e seus efeitos, preocupado com problemas de identidade de grupos conforme reproduzidos na linguagem (...), aberto à diversidade de todos os tipos e com restrições a soluções simplistas para problemas complexos (...).

As teorias pós-coloniais, sobretudo nos direcionamentos dados por teóricos como Gayatri Spivak (1990) e Homi Bhabha (1998), são informadas pela psicanálise e pelas teorias de discurso e manifestam preocupação com os efeitos do colonialismo nas estruturas sociais e nas formações discursivas. Homi Bhabha dialoga com diversas tradições teóricas, destacando-se dentre elas, a psicanálise, o pós-estruturalismo e a desconstrução derrideana, para investigar a ação da autoridade colonial e a dinâmica da resistência que ela gera. Bhabha teoriza as identidades coloniais como fluidas e agonísticas, capturadas no movimento de perpetuação do Eu e desejo pelo Outro, apontando para a ambivalência do discurso da autoridade e sua própria gestação do discurso da resistência (Loomba 1998). 
Umas das contribuições da teoria pós-colonial de Bhabha para os estudos culturais, de interesse para o nosso trabalho, é a sua releitura do conceito de hibridização textual bakhtiniano. Bakhtin (1981:358) havia definido o conceito da seguinte forma:

(...) a hibridização (...) é uma mistura de duas linguagens sociais dentro dos limites de um único enunciado; um encontro, dentro da arena de um enunciado, entre duas consciências lingüísticas diferentes, separadas uma da outra por uma época, pela diferenciação social ou por algum outro fator.

A hibridizaçao, tal como formulada por Bakhtin, é a propriedade de ambigüidade da linguagem que, ao mesmo tempo, é a mesma e é diferente, e cuja proposta não é fundir dois pontos de vista diferentes num enunciado, mas colocá-los em dissonância numa situação dialógica, de conflito, em que o desfazer do discurso da autoridade e a abertura são traços preponderantes (Young 1995). A apropriação de Bhabha do conceito de hibridização bakhtiniano se faz, segundo Young, exatamente neste ponto da subversão da autoridade para o contexto dialógico do colonialismo. Bhabha (1998:165) assim define o conceito de hibridismo:

O bibridismo é uma problemática de representação e de individuação colonial que reverte os efeitos da recusa colonialista, de modo que outros saberes "negados" se infiltrem no discurso dominante e tornem estranha a base de sua autoridade - suas regras de conbecimento.

Para Young, há, no hibridismo de Bhabha, um movimento de transformação do híbrido intencional de Bakhtin para “(...) um momento ativo de desafio e resistência contra um poder cultural dominante", cujo valor político de mudança está na "(...) re-articulação, ou tradução, de elementos que não são nem o Um, nem o Outro mas algo mais que contesta os termos e territórios de ambos" (Bhabha apud Young 1995:23).

Para Bhabha, uma das estratégias discursivas do hibridismo é a mímica ou

(...) signo de uma articulação dupla, uma estratégia complexa de reforma, regulação e disciplina que se "apropria" do Outro ao visualizar o poder. (...) signo do inapropriado (...) uma diferença (...) que ordena a função estratégica dominante do poder colonial, intensifica a vigilância e coloca uma ameaça imanente tanto para os saberes "normalizados" quanto para os poderes disciplinares (Bhabha 1998:130) 
A mímica, nos termos de Bhabha, é construída em torno de uma ambivalência, produzindo o excesso e o deslizamento que, não apenas contestam o discurso colonial, mas produzem nele um estado de instabilidade e incerteza, através da dupla articulação da semelhança e da ameaça.

Simon (1999) faz um paralelo esclarecedor entre os conceitos de Bakhtin e Bhabha. O conceito de Bakhtin não é apenas um conceito descritivo para dar conta da plurivocidade do romance, mas a expressão de um valor moral, afirmando a multiplicidade das identidades e opondo-se ao monopólio da verdade única. Para Bhabha, cuja reflexão provém de um mundo póscolonial, o hibridismo “(...) se produz na zona de negociação, de contestação e mudança, uma 'cultura de tradução' que provoca um curto circuito nos esquemas de alteridade para exprimir a força das identidades contemporâneas" (Simon 1999:39-40). Nas palavras de Simon, Bakhtin e Bhabha, em situações históricas e políticas diferentes, refletem sobre o hibridismo como abertura de espaços novos de enunciação que redesenham a geometria das relações culturais contestando sua hierarquias de poder. Simon (1999:39) esclarece os posicionamentos políticos dos autores:

Quando se sabe que Bakbtin elaborou o essencial de sua obra em exílio forçado nos piores anos da ditadura stalinense é que se compreende toda a força de suas análises. (...) O espaço de reflexão de Homi Bhabba é o mundo pós-colonial, e mais particularmente as desigualdades econômicas e culturais que são herança da época colonial.

O hibridismo como forma política de desafio e resistência a um poder cultural dominante se manifesta nas práticas de significação, através dos eventos discursivos das instituições, dentre eles, as produções textuais. Assim, retomando uma longa afiliação de teóricos, dentre eles, Bakthin, Bhabha incorpora às abordagens do autoritarismo, colonialismo e desigualdades decorrentes deles a dimensão discursiva, através de sua proposta, compartilhada com a de outros teóricos, como Laclau e Mouffe, de examinar "a linguagem da textualidade e do discurso" (Bhabha 1998:30). Como Bhabha (1998:183) afirma, citando o trabalho de Gayatri Spivak, trata-se de negociar o espaço pós-colonial:

revertendo, deslocando e apropriando-se do aparelho de atribuição de valores, constituindo-se um espaço de catacrese: palavras e conceitos usurpados do seu significado correto, 'uma metáfora conceitual sem um referente adequado' que subverte seu contexto de ocorrência. 
A linguagem da textualidade e do discurso constitui objeto de investigação da análise crítica do discurso que também se apropria do conceito de hibridização bakhtiniano e, mais recentemente, propõe um diálogo com teorias discursivas da diferença e da abertura do social. Nesse sentido, o arcabouço teórico do pós-colonialismo tem assim muito a contribuir para esse diálogo. Todavia, retomando as reflexões levantadas pelos estudos culturais, a investigação da linguagem da textualidade não pode substrair-se às especificidades locais e históricas e a questões de classe, gênero, raça e etnia que solicitam uma abordagem de textos no âmbito de práticas de produção, consumo e circulação. Como negociar, então, uma interação fluida entre os estudos pós-coloniais, os estudos culturais e a análise crítica do discurso? Em outras palavras, como investigar formas culturais emergentes, híbridas, a partir de formas de conhecimento capazes de capturar esse hibridismo, examinar a linguagem de sua textualidade e localizar sua emergência no contexto histórico e local da sua ocorrência?

Para abordar essas e outras questões, propomos aqui uma reflexão sobre a possibilidade de diálogo entre a proposta da analíse crítica do discurso e as teorias culturais e pós-coloniais, em especial o hibridismo cultural de Bhabha, para dar conta de um objeto de estudo que se caracteriza enquanto produção textual híbrida. Voltemos, então, nossa atenção para a proposta da análise crítica do discurso.

\section{A análise crítica do discurso}

Fairclough (2000) entende a análise textual, de acordo com sua proposta de análise crítica do discurso, como análise da organização dos textos, compreendendo dois tipos complementares de análise: a lingüística e a intertextual. $\mathrm{Na}$ análise lingüística, parte-se do pressuposto de que o texto se apropria seletivamente dos sistemas lingüísticos e, na análise intertextual, do pressuposto de que o texto se apropria seletivamente de ordens do discurso, entendidas como convenções particulares de práticas convencionalizadas (gêneros e discursos).

A lingüística sistêmica tem um papel crucial no primeiro tipo de análise, em função do seu pressuposto da linguagem enquanto escolha ou seleção de opções dos sistemas que constituem os potenciais de significado, abrangendo a inclusão e a exclusão. A análise intertextual, inspirada 
neste pressuposto, verá o texto como escolha num nível de análise diferente, envolvendo uma seleção de opções dentro do que se pode chamar de potencial intertextual de uma ordem de discurso, ou de repertório disponível de gêneros, discursos, e narrativas, estas últimas entendidas como tipos de "história socialmente ratificada" (Fairclough 2000:208).

O foco na heterogeneidade dos textos remete a práticas e relações instáveis de domínios sociais e à noção de hibridização dos gêneros discursivos, apropriada de Bakthin. Gênero discursivo é tomado como "(...) conjunto relativamente estável de convenções (...) associado a um tipo de atividade ratificada socialmente e que a encena parcialmente (...)" (Fairclough 1992:126). É o sistema de gêneros de uma determinada sociedade numa época determinada que determina as combinações e as configurações que dão tessitura aos discursos. São também os vestígios, em um gênero discursivo, de outros gêneros discursivos, que nos permitem refletir sobre os movimentos interdiscursivos das práticas e sobre as relações de poder entre estas.

Como Fairclough (2000) aponta, a lingüística sistêmica possibilita a análise não apenas do material textual, das escolhas efetivamente materializadas no texto, mas também das exclusões, omissões e formulações potenciais. Tal análise textual não é, entretanto, puramente descritiva, mas pressupõe o elemento de interpretação dessas escolhas, em permanente diálogo com o contexto sociocultural em que se inserem. Nesta perspectiva de análise crítica do discurso, Magalhães (2000) é um trabalho pioneiro no Brasil sobre a reflexão do discurso médico/paciente, em especial sobre a constituição dos sujeitos as relações de poder neste discurso.

$\mathrm{Na}$ análise da dimensão da prática social, o conceito de hegemonia gramsciano proporciona um modelo, ou modo de analisar a própria prática discursiva como modo de luta hegemônica, reproduzindo, reestruturando ou desafiando as ordens de discurso existentes. É a dimensão da prática social que torna possível o diálogo da análise crítica do discurso com os estudos culturais e os estudos pós-coloniais, ambos também preocupados com as representações culturais híbridas nos textos. As dimensões do texto e da prática discursiva podem trazer uma contribuição inestimável para tais abordagens, oferecendo a elas um método de análise textual, baseado na hibridização dos gêneros discursivos e nas escolhas lexicais, gramaticais e de estrutura textual associadas a esses gêneros. 


\section{A análise crítica do discurso em diálogo com teorias culturais e pós-coloniais}

No Brasil, trabalhos afiliados à análise crítica do discurso têm realizado de forma bem sucedida um diálogo com os estudos culturais e outras áreas do conhecimento. Dentre eles, é digno de menção Rajagopalan (2000), sobre as implicações de noções do neo-pragmatismo, em especial a noção de contingência identitária num mundo pós-industrial, para a análise crítica do discurso. Ainda, sob uma outra perspectiva teórica, embora reconhecendo o potencial da teoria de Fairclough, projetos como os desenvolvidos por Cavalcanti (1999) focalizam contextos de minorias lingüísticas, problematizando representações estabelecidas na cultura brasileira, como o chamado "mito do monolingüismo no país" que oblitera a existência e promove a "invisibilidade" de diversas comunidades de minorias multiculturais no Brasil.

No contexto internacional, diferentes pesquisadores também vêm reconhecendo o trabalho desenvolvido pelos analistas críticos do discurso e sua viabilidade de integração a outros referenciais teóricos. Barker e Galasínski (2001), por exemplo, apesar de afiliados à teoria da semiose derrideana argumentam que, apesar do seu constante deslocamento, na prática social as práticas de significação são reguladas e estabilizadas, pelo menos temporária e parcialmente, para propósitos pragmáticos. Para esses autores, a análise crítica do discurso constitui referencial teórico pertinente, com ferramentas metodológicas e procedimentos lingüísticos adequados para as análises discursivas das representações culturais, promovidas pelos estudos da cultura.

Mais recentemente, Chouliaraki e Fairclough (1999) reelaboram a proposta de Fairclough (1992), refletindo que a vida social contemporânea e suas práticas, dentre delas o discurso, são objetos de estudos bastante complexos que não podem ser abordados de uma única perspectiva teórica e metodológica. Propõem, então, a análise crítica do discurso como área transdisciplinar capaz de produzir conhecimento sobre o discurso a partir de sua possibilidade de trânsito entre as teorias sociais críticas e as teorias de discurso, dentre elas as narrativas da modernidade tardia. Para os autores, a pesquisa transdisciplinar implica na internalização de uma teoria por outras, fazendo-as trabalhar dentro de uma lógica própria da primeira, mas sem a reduzir à lógica das outras. Assim sendo, a análise crítica do 
discurso pode manter a lógica da lingüística sistêmica, sua base de análise lingüística, ao mesmo tempo em que internaliza a lógica de outras teorias, em especial de teorias sociais críticas, das quais são apropriados muitos dos conceitos sobre os quais passamos a refletir.

Com relação à proposição de que a vida social é constituída de práticas, Chouliaraki e Fairclough a expandem definindo prática enquanto "formas de hábito, ligadas a tempos e lugares particulares, em que as pessoas aplicam recursos (materiais ou simbólicos) para agirem juntas no mundo (1999:21)", percebendo, ainda, a ambigüidade do conceito que simultaneamente significa ação social, associada um espaço e tempo determinado, e ação cristalizada como permanência relativa, portanto, associada a uma maneira habitual de agir. Para os autores, esta ambigüidade é produtiva, sinalizando para um posicionamento intermediário das práticas entre estruturas e eventos e estruturas e agenciamento, pois as práticas têm traços de ambos os elementos dos pólos apontados.

Por isso, Chouliaraki e Fairclough (1999) focalizam conjunturas em contraste com estruturas e eventos. Estruturas são definidas como condições que a experiência anterior, de longo prazo, traz para a vida social e que também são transformadas por esta lentamente; eventos como acontecimentos e ocasiões únicos e imediatos da vida social e conjunturas como “(...) reuniões relativamente duráveis de pessoas, materiais, tecnologias e, portanto, práticas (em seu aspecto de permanências relativas) em torno de projetos sociais no sentido mais amplo do termo" (p.22). O foco nas conjunturas traz a vantagem da busca de efeitos, através do tempo, não apenas de eventos singulares mas de "(...) séries de eventos ligados conjunturalmente tanto na sustentação quanto na transformação (re-articulação) de práticas" (p. 22).

Os conceitos de estrutura e sistema, rejeitados por teorias informadas pelo pós-estruturalismo, são retomados por Chouliaraki e Fairclough (1999), já que a proposta dos autores vai de encontro à noção de abertura total do social, calcada na preponderância da discursividade das práticas sociais. Giddens (apud Cassell 1993) é esclarecedor sobre a questão. O autor argumenta que as noções de estrutura e sistema, se adequadamente conceituadas de modo a diferenciá-las do uso a que foram postas especialmente nas teorias de estruturalismo e funcionalismo, são necessárias para as teorias sociais. Para Giddens, no estruturalismo, sistema sempre aparece como 
uma característica definidora de estrutura que, por sua vez, significa o conjunto de dependências entre os elementos da língua (langue). No funcionalismo, estrutura refere-se a padrões de relações sociais e sistema ao funcionamento per se destas relações. Tanto numa tradição quanto na outra, segundo Giddens, há uma tentativa de excluir o tempo, ou as interseções entre tempo e espaço, da teoria social, através da distinção entre sincronia e diacronia.

Giddens (apud Cassell 1993) também aceita que a estrutura não existe no tempo e no espaço, mas apenas como "propriedade estrutural" constituinte, em determinados momentos, do sistema social, entendido como "totalidade estrutural". Para ele, é possível analisarem-se as estruturas associadas à duração histórica de práticas por elas organizadas recursivamente e a "amplitude" espacial destas práticas, entendidas como instituições. Estas noções, de acordo com a leitura do teórico social, são distintas dos conceitos conforme usados no estruturalismo e, mais tarde, desconstruídos no pós-estruturalismo. De fato, parecem constituir uma saída para uma análise discursiva das conjunturas sociais, conforme proposto por Chouliaraki e Fairclough (1999), com a desejada internalização parcial da "abertura do social”, mas mantendo uma restrição parcial, na busca do entendimento das condições que regulam a continuidade de conjunturas, ou a transformação destas conjunturas em outras, de acordo com projetos sociais hegemônicos.

A discussão iniciada aqui em torno dos conceitos de práticas, estruturas, sistemas, e conjunturas, é produto da articulação da análise crítica do discurso com as teorias sociais. A articulação com abordagens discursivas de tradição lingüística, como já vimos, se dá com a lingüística sistêmica hallideana, que vê a linguagem sob uma perspectiva sócio-semiótica. Halliday (em Halliday \& Hasan 1993) toma o conceito de semiótica como o estudo de sistemas de signos, para se distanciar da concepção atomística de signo enquanto signo em si e por si só. Para o autor, a lingüística é um tipo de semiótica, um aspecto do estudo do significado, o qual não se reduz apenas à linguagem e está em várias outras formas da cultura; esta, por sua vez, considerada como um conjunto de sistemas semióticos ou de sistemas de significado que se inter-relacionam. Os signos, para Halliday, são redes de relações que operam os sistemas de significado. A perspectiva de linguagem hallideana é, pois, semiótica, no sentido de que a linguagem é uma dentre os muitos sistemas de significado que, interrelacionados, 
constituem a cultura. O termo social é usado para referir-se, simultaneamente, ao sistema social, tomado como sinônimo de cultura e à relação entre a linguagem e a estrutura social, considerada como um aspecto do sistema social. A perspectiva de relacionar a linguagem com um aspecto da experiência humana, a estrutura social, é explicada através do interesse na dimensão social da linguagem, em que o conhecimento é construído e reproduzido nos contextos sociais das instituições, abrangendo as relações sociais, definidas nos sistemas de valores e ideológicos das culturas.

Chouliaraki e Fairclough também dialogam com teorias sociais cuja concepção de social pressupõe a impossibilidade do fechamento deste (Laclau e Mouffe, apud. Fairclough \& Chouliaraki 1999). Informados pelas teorias derrideanas e lacanianas, Laclau e Mouffe (cf. Barker \& Galasínski 2001) criticam o essencialismo, fundacionalismo e reducionismo do marxismo. Barker \& Galasínski (2001:11) afirmam que Laclau e Mouffe: “(...) argumentam que o 'social' não épara ser pensado como totalidade mas como um conjunto de agregados, relacionados contingencialmente, de diferenças articuladas ou 'suturadas' juntas."

O pensamento derrideano - sobre semiose como um jogo infinito de significação que rejeita a fixação do sentido - é crucial para entendermos os rumos das teorias sociais, culturais e pós-coloniais na contemporaneidade. Barker \& Galasínski (2001:10) resumem bem a concepção da teoria desconstrucionista de Derrida:

Derrida argumenta que já que o significado é gerado através do jogo de significantes a não em referência a um mundo-objeto independente, ele jamais pode ser "fixo". As palavras têm múltiplos significados, incluindo os ecos ou vestígios de outros significados de palavras relacionadas, em outros contextos. A linguagem não é representacional e o significado é inerentemente instável de tal forma que ele desliza constantemente. Assim, por differance, sugere-se um sentido de "diferença e adiamento". A produção de sentido no processo de significação é continuamente adiada e suplementada no jogo do mais-do-que-um. A suplementaridade contínua do significado, a substituição e adicionamento contínuos de significados através do jogo de significantes desafia a identidade dos ruídos e marcas com significado fixo. O significado dos significantes jamais poderá ser idêntico a uma entidade fixa à qual uma palavra se refere porque o suplemento adiciona e substitui significados.

Barker \& Galasínski (2001) reconhecem a autoridade de Derrida nos estudos culturais, em especial, na adoção dos conceitos anti-representacionalistas, construtivistas sociais, anti-essencialistas e de desconstrução tex- 
tual. Essa autoridade faz-se presente na noção de identidade como instável e como processo, ao invés de entidade, nas teorias de representação de Hall (1997), ou na teoria pós-colonial de Bhabha (1994), em que as culturas são zonas de negociação e hibridização, as identidades e as identificações são lidas como espaços liminares, de hibridismo, ao invés de entidades fixas e estáveis (Barker “Galasínski, 2001:11). Mas os autores também refletem que

Em termos analíticos, a desconstrução nos estudos culturais fica fadada a um textualismo exacerbado que rejeita qualquer tipo de trabalho (...) empírico. (...) Em termos políticos, a desconstrução ilimitada de categorias fundacionais, o infindável desdobramento do significado, a indeterminação de conceitos como justiça ou identidade têm uso prático limitado.

Chouliaraki e Fairclough (1999) também reconhecem que a principal contribuição de Derrida para o pensamento contemporâneo sobre a linguagem foi o entendimento da lógica específica do semiótico, com a noção do permanente deslocamento e adiamento do significado. Para os autores, a lingüística sistêmica faz uma formulação diferente da abertura da lógica do semiótico, denominada semio-lógica (semo-logic) por Hasan (apud Chouliaraki e Fairclough 1999:125):

a lógica do semiótico produz signos verbais e enunciados (a gramática lexical, nos termos da lingüística sistêmica) que constituem os significados, que são produtores de significado, de tal forma que qualquer diferença de signo verbal ou enunciado implica numa diferença de significado, embora o sentido desta diferença seja um problema de negociação social (por exemplo, a intenção do falante não determina a interpretação do ouvinte).

Chouliaraki e Fairclough tomam esta lógica do semiótico como uma especificação da noção derrideana do jogo infinito dos significantes, ou como poder de produção de significado do semiótico. Assumem, portanto, a postura teórica nômade a que nos referimos anteriormente ou de teóricos em "um reinado intermitente, baseado no domínio, mesmo que parcial e fragmentado, de diferentes teorias vinculadas a diferentes tradições". Como lingüistas aplicados, internalizam a teoria de semiose derrideana na lógica do semiótico da teoria lingüística sistêmica sem, entretanto, reduzir esta última à primeira. Remetendo-se a Hasan, eles acrescentam que:

de acordo com esta visão, as práticas sociais envolvem a operação simultânea de mecanismos diferentes, dentre os quais a semiose; nenhum mecanismo trabalba sozinho, todos são mediados 
pela operação dos outros. As possibilidades infinitas da semiose são constrangidas e limitadas pelos efeitos dos outros mecanismos dentro das práticas sociais - a semio-lógica (semo-logic) e a socio-lógica (socio-logic) têm interseção em contextos específicos de produção de significado (1999:125).

Assim, a lógica do semiótico teria uma certa abertura mas com restrições, pois dá origem a diferentes jogos para grupos de agentes sociais diferentes em práticas sociais diferentes; dito de outra maneira, esta seria uma visão em que formas diferentes de vida social ou tipos diferentes de sociedade originam formas diferentes de antagonismo, implicando em graus e formas diferentes de acesso às possibilidades do semiótico.

A lingüística sistêmica, fundamentada em preceitos das teorias sociais, constitui um arcabouço teórico e metodológico adequado para os propósitos da ACD, de foco no "aspecto discursivo de conjunturas de práticas sociais" (p.137); entretanto, para os autores, ela só consegue operacionalizar a dialética da semiótica parcialmente, porque tende a se direcionar para a semiótica em oposição a outros momentos do social, e para o sistema em vez da instância (ou texto), além de não reconhecer a estruturação social do hibridismo semiótico - as ordens do discurso - como um sistema em si.

Faz-se necessário, portanto, reconhecer, no aspecto discursivo, ou semiótico, de uma prática, dois elementos que se articulam, os gêneros e os discursos, cujo conceito é refinado pelos autores:

(...) gênero (...) (é) uma estruturação discursiva específica ou ordenamento de uma prática social, um recurso regulador através do qual as relações de poder são manifestas como formas de controle; (...) discurso (...) (é) uma construção ou representação de uma prática social a partir de uma perspectiva particular de outra prática social (...) (p.144).

Uma propriedade dos gêneros no nível da conjuntura é o hibidrismo, a mistura de convenções associadas a gêneros vinculados, por exemplo, a eventos discursivos que se caracterizam pelo uso predominante da linguagem falada, com convenções associadas a gêneros vinculados a eventos discursos caracterizados pelo uso predominante da linguagem escrita, em tempos e espaços sociais diferentes. É esta mistura que confere aos textos sua característica de ambivalência. Fairclough (cf. Mills 1997) reitera que o significado textual pode ser indeterminado e que as unidades de um 
discurso podem se abrir para interpretações diferentes, pois, ao se integrar a outro texto, ou ao se recontextualizar, o texto cria uma certa disjunção em relação à rede intertextual. Lembrando Bakhtin, é a mistura e, ao mesmo tempo, o encontro, na arena do enunciado, de múltiplas linguagens sociais diferentes. Ou, na visão de Bhabha, a representação, através da infiltração, de saberes negados no discurso dominante que, por assim dizer, o desautorizam. A preocupação central da análise crítica do discurso (Fairclough 1992; Chouliaraki e Fairclough, 1999) tem sido as formas do novo capitalismo e seus efeitos no momento discursivo das práticas sociais, em especial em relação às questões de relações de classe econômica e social. Assim sendo, a teoria tem se mostrado eficiente para dar conta de gêneros de discursos (midiático, em especial) em que mais claramente estas questões se manifestam.

Nosso interesse são os efeitos das formas deste capitalismo nas questões culturais relativas ao pós-colonialismo, em especial as formas conjunturais de exclusão das comunidades de afro-descendentes na sociedade brasileira. Trata-se, compartilhando as percepções de Cavalcanti (1999), de problematizar o "mito do monolingüismo," e do monoculturalismo prevalecentes no Brasil, dando ouvidos a vozes que buscam, através de diferentes formas, gêneros e políticas de manifestação, uma inserção nos debates que definem políticas públicas no país. O hibridismo cultural destas comunidades se manifesta, dentre outras formas, através do hibridismo textual em gêneros de diversos discursos que se revelam transnacionais e transculturais, na medida em que buscam dialogar com manifestações culturais de outras comunidades como forma de construir sua própria identidade, muitas vezes reelaborando elementos da cultura de massa e cultura popular. Nossa argumentação é que a análise crítica do discurso, por seu trânsito nas áreas sociais, culturais, e pós-coloniais, pode possibilitar a desejada ampliação do olhar e da escuta dessas vozes e, simultaneamente, a necessária focalização do aspecto discursivo da prática social de produção e consumo também dos gêneros do discurso literário dos afro-descendentes brasileiros, os quais se articulam em torno de um projeto de afirmação identitária sociocultural e pós-colonial ${ }^{1}$.

\footnotetext{
1 Há controvérsias sobre a condição pós-colonial brasileira e latino-americana (cf. Loomba 1998). Estamos tomando a condição sociocultural brasileira enquanto pós-colonial seguindo a vertente dos estudos pós-coloniais “(...) interessada na focalização de relações de poder que até recentemente têm sido reprimidas, idealizadas ou universalizadas [que] (...) permite (...) buscar na história da
} 


\section{Um discurso emergente num Brasil pós-colonial}

O que expusemos acima demonstra a possibilidade de trânsito por espaços teóricos híbridos. Essa articulação nos oferece, antes de mais nada, o reconhecimento de discursos que postulam formas de resistência diante de discursos hegemônicos. É esse o caso de manifestações culturais brasileiras que buscam questionar um sistema de valores e conceitos em torno da obliteração das diferenças raciais e sua inserção no espaço político e cultural da nação. Pelo prisma das teorias pós-coloniais, podemos capturar experiências de identidades que, apesar de não serem sujeitas a fenômenos como a diáspora, o exílio ou o banimento, representam subjetividades póscoloniais, as quais “tem de falar 'do lugar em que estão', que é também um espaço fragmentado seja do ponto de vista ideológico, político ou emocional" (Loomba 1998:181). Há neste ponto uma necessária expansão da abordagem de Bhabha. Como bem comenta Young (1990:152), embora Bhabha tenha possibilitado uma descrição extremamente sutil das condições pós-coloniais, desautorizando outras muito simplistas, suas reflexões apontam para “(...) a resistência ou a submissão (...) em termos de um sujeito colonial geral (...) dentro das demandas de um esquema geral das condições do discurso colonial" A construção dessas identidades pós-coloniais, os estudos culturais nos mostram, se dá a partir de configurações locais e históricas que possibilitam a manifestação através de textos e gêneros que as acolhem. A análise crítica do discurso nos oferece um instrumental de análise textual e intertextual, que se constitui ele próprio em abordagem teórica da linguagem da textualidade.

O texto escolhido para o exercício proposto, de operacionalização dessa articulação analítica, deve sua escolha ao fato de se tratar de um pequeno poema - gênero que o classifica e rotula - publicado pelo escritor brasileiro contemporâneo, Cuti, membro na década de setenta do Centro de Cultura e Arte Negra (CECAN), de São Paulo, fundador da organização literária Quilombhoje e da antologia anual, Cadernos Negros.

humanidade exemplos da dominação e suas conseqüências, assim bloqueando efetivamente a resposta conservadora que descarta (...) o fenômeno 'pós-colonial' como representativo da nossa identidade ou dos nossos valores culturais" (Robinson 1997:15). 


\title{
Para ouvir e entender "Estrela"
}

\author{
Se o Papai Noel \\ não trouxer boneca preta \\ neste Natal \\ meta-lhe o pé no saco
}

Uma análise informada por uma análise crítica do discurso transdisciplinar nos permite observar já, no título do poema, uma forma de intertextualidade, não identificada pela teoria como hibridismo de gêneros diferentes, mas que, no nosso entender, acionará o mecanismo para este hibridismo: a provocação ao poema Ora (direis), Owir estrelas, de Olavo Bilac, em especial, ao último verso do poema "Capaz de ouvir e de entender estrelas", parcialmente reproduzido no título Para ouvir e entender "estrela". O item lexical "estrela", no singular, permitirá a recontextualização do último verso de Bilac no espaço da linguagem instrucional, típica de um manual, já que parece tratar-se do título de uma instrução para habilitar alguém a ouvir e entender a "Estrela", a tradicional fábrica de brinquedos. Neste sentido, o verso, elemento integrante do gênero "poema," é transformado numa instrução, elemento constituinte do gênero "manual de instruções," por sua vez inserido no gênero "poema", no qual os significantes sinalizando processos mentais - "ouvir" e "entender" - são deslocados para outros sentidos para além do poema de Bilac. A solução dada no texto de Bilac para ouvir e entender é um processo também mental, "amar": "Amai para entendê-las! Pois só quem ama pode ter ouvido Capaz de ouvir e de entender estrelas"." Ouvir" e "entender", no texto de Cuti, são processos ligados a um processo material, a uma ação prescrita no manual de instruções: "meta-lhe o pé no saco".

No texto de Cuti, as estrelas do firmamento, topos caro a Bilac e ao cânone literário que o reconhece, são deslocadas para a 'Estrela', a fábrica de brinquedos, significação recuperada através da interpretação semântica que a rede coesiva lexical "estrela, Papai Noel, boneca, Natal, saco" pode desencadear no contexto do natal brasileiro. Podemos aqui expandir a reflexão de Halliday e Hasan (1976), sobre a transformação inevitável da identidade de termos em rede coesiva à medida que se estabelece a continuidade da relação semântica entre esses termos, reconhecendo, nesta reflexão, uma certa abertura para a possibilidade do deslocamento, do excesso 
no processo de significação, já que os autores admitem que cada elemento que reitera um signo numa rede de significação modifica ou acrescenta outros elementos à significação daquele signo.

A "estrela" do poema de Cuti pode, assim, ser lida enquanto a fábrica de brinquedos. Mas ela é, simultaneamente, também construída através da "mímica", de repetição estranha do signo, através de dois dos elementos da rede coesiva que a constrói. O primeiro é a "boneca preta", objeto do processo material "trazer", que tem como participante o Papai Noel e um segundo participante potencial nesta estrutura de transitividade, "lhe trazer, nos trazer", introduzida pela estratégia da mímica, ou de continuidade produtora de ambigüidade na rede coesiva, evocando signos múltiplos: é a boneca de pano preta, brinquedo inexistente no saco do Papai Noel; contudo, peça importante no processo de identificação de crianças negras e um dos elementos para a desmistificação da "elaboração ideológica de alto refinamento hipócrita" (Cuti, 1995: 903) da democracia racial brasileira. É, também, a boneca preta "Babalotim", do Afoxé, manifestação profana do candomblé jeje-nagô durante o carnaval. De acordo com Joli Campello, em A Folia em voz Nagô, a boneca nagô, "representante dos Ibeji (Cosme e Damião), é conduzida por um meninote, exímio dançarino capaz de executar os complicados passos da coreografia que reverencia a boneca que vai na frente, seguida pelo Obá (rei), pela rainha e pelo quimboto (feiticeiro)". Pode, ainda, ser relacionada com feitiçaria vodoo, através do deslocamento do afoxé pela diferença que gera a paranóia.

O segundo é a palavra "saco", que se abre para a significação do campo semântico do erotismo, pois remete ao órgão sexual masculino, e sua associação com o desejo por uma "boneca preta", entrando em rede coesiva também com o item lexical "meta" (do processo material "meter" em sua conotação sexual). Retomando nossa interpretação anterior, de provocação de Cuti ao poema de Bilac, podemos propor que há uma transformação da rede coesiva de processos mentais do poema de Bilac "ouvir e entender", relacionada a "amar", também processo mental, numa rede coesiva de processos materiais pela associação com "meter", processo material, que acrescenta a "amar" a materialidade do sexo. Cuti (2000:271), definindo o erotismo enquanto "transgressão baseada no desejo impedido de encontrar sua satisfação", posiciona a poesia negra na contra-mão dos valores moralistas das culturas brancas européias, repressoras das manifestações da sexualidade, incluindo as da linguagem. Em análise de vários poemas 
publicados nos Cadernos Negros, Cuti recupera valores originados das culturas africanas, distintos daqueles das culturas brancas, que permitem aos poetas introduzir no espaço da poesia, sob o prisma do erotismo, questões importantes; no caso do poema ora em análise, a afirmação das identidades negras e de rituais sagrados associados às culturas africanas. Cuti também lembra que a repressão à sexualidade se faz sentir de forma mais clara nas instituições da família, escola e religião. $\mathrm{O}$ autor explica que o projeto dos poetas negros, ciente disso, faz um releitura destas instituições, “(...) revelando, com certa ironia, seu erotismo camuflado” (Cuti 2000:279). Podemos resgatar isso em seu próprio poema, via o erotismo da boneca preta no natal da instituição religiosa cristã, que introduz a necessidade de identificação racial através do brinquedo e, simultaneamente, o desejo sexual pela mulher negra.

Mais um elemento para a interpretação da recontextualização do gênero manual de instruções, do tipo manual de montagem ou funcionamento de brinquedos no poema, são as duas orações vinculadas numa relação hipotática condicional, típicas da linguagem instrucional, também calcada no padrão de problema-solução (Hoey 2001). Uma análise da perspectiva da organização da mensagem neste texto mostra que o tema oracional, qual seja a oração condicional, recebe proeminência e estabelece as bases interpretativas para a segunda oração do texto, sinalizando para problemas de funcionamento, podemos nos perguntar, dos brinquedos? ou da própria Estrela? ou do que os dois representam em termos de práticas de identificação e significação na cultura brasileira? Esta última alternativa parece a mais viável, já que a condição negativa - a possibilidade de Papai Noel não trazer a boneca preta - parece constituir um problema cuja solução demandará uma resposta afirmativa contundente ("meta-lhe o pé no saco").

O poema de Cuti, em provocação ao de Bilac, evoca signos vinculados aos valores da poesia bilaquiana, mas respondendo a estes valores com a escolha de colocações associadas a valores alternativos, aos quais se vinculam uma linguagem associada a gêneros da convivência cotidiana que prevêem a ocorrência do "meta-lhe o pé no saco" (formulação híbrida que incorpora traços de uma gramática autorizada). Mas não é apenas a linguagem de uma estética alheia que é desautorizada pela linguagem de Cuti; esta última também é desautorizada através da recontextualização das colocações "pé no saco" e "meta o pé”. O uso naturalizado destas colo- 
cações pressupõe, no caso de "pé-no-saco", alguém ou algo entediante, monótono, como a estrela e suas bonecas brancas, e no de "meta o pé", a recusa desses valores de forma contundente. A proposta de Cuti, de construção de uma identidade negra via resistência a tudo que está convencionalizado por uma sociedade que apaga as marcas do negro, se faz, trazendo a linguagem do manual para o poema; desautorizando a estética poética de Bilac; contestando valores associados a instituições brancas, como o natal do Papai Noel, as bonecas brancas e a negação da sexualidade; e introduzindo um espaço de negociação para a linguagem do cotidiano e do erotismo, a fragmentação das identidades brasileiras, e a dessacralização ou carnavalização do natal e do amor cristão. Cumpre esclarecer, aqui, que Cuti fala a partir do seu lugar de homem, negro, intelectual, participante de formas de agenciamento cultural que buscam ações afirmativas na sociedade brasileira. Não é esta uma leitura que se faça extensiva ao lugar de enunciação da mulher negra na sociedade, embora Cuti (2000:281) observe “ (...) nas poetas negras uma maior aproximação ritual com a poesia e, conseqüentemente, a tendência a não distanciar a sexualidade do todo", traço que se pode recuperar nos poemas das escritoras negras afiliadas aos Cadernos Negros ${ }^{2}$.

O projeto de vários autores ligados à Quilombhoje, nas palavras de Cuti (1995), é buscar formas de expressão de valores culturais inexistentes ou reprimidos no português do Brasil em função de padrões hegemônicos de poder que o transformaram, por assim dizer, em língua estrangeira para os seus próprios falantes, cristalizada com ideologias e preconceitos, dentre eles o racial. A ideologia da democracia racial e a introjeção do preconceito racial pelos próprios negros é uma das estratégias de expressão e dominação desta língua cristalizada, as quais o escritor considera difícil de serem desmistificadas, por terem sido elaboradas com requintes de hipocrisia. Assim elabora Cuti seu projeto poético-político:

Historicamente, você começa a notar, na estrutura da língua, configurações que são tremendamente racistas, configurações mesmo de frases, de sintaxes, de noções que vão sendo repetidas através da história brasileira, e que elas acabam também servindo para cristalizar a discriminação e o racismo. A língua portuguesa falada no Brasil é um grande sustentáculo da ideologia. Quando não só eu, mas outros escritores ... enveredamos por um caminho de criar novas

\footnotetext{
2 Lembramos que a análise aqui proposta não pretende fazer uma incursão aos estudos psicanalíticos, cuja abordagem deste corpus seria feita a partir de diferentes pressupostos teóricos.
} 
palavras, estamos buscando exatamente isso, buscando uma expressão capaz de traduzir determinados sentimentos, determinadas atitudes nossas perante a vida, que a lingua portuguesa não tem. Por outro lado, do ponto de vista também dos valores culturais, existem muitas palavras ainda hoje que são utilizadas em determinadas áreas, por exemplo no samba, mesmo no candomblé, que são palavras que não foram para o dicionário (Cuti, 1995:904).

Em "Para ouvir e entender "Estrela", a boneca preta está ausente do saco de presentes do Papai Noel e do estoque da fábrica de brinquedos, assim como estão ausentes na linguagem poética manifestações de desejos eróticos; em ultima instância, estão ausentes do repertório cultural de toda uma comunidade valores alternativos, associados aos padrões não hegemônicos das culturas negras. A interpelação direta ao interlocutor - homem? mulher? - meta-lhe pé no saco - revela o esgotamento de um modelo que, preconizando a sensibilidade para "entender e ouvir estrelas," construiu uma estética visual da palidez.

Uma leitura do poema de Cuti, como procuramos mostrar através do hibridismo de gêneros (o poema Para ouvir e entender "estrela" com o manual de brinquedos da Estrela) e de discursos (literário, religioso e técnico), permite-nos reconhecer uma outra forma alternativa de discurso que, através da mímica manifesta nesse hibridismo, deseja desestabilizar não apenas as palavras, mas o próprio poema enquanto gênero de um discurso literário alternativo, associado a práticas de produção textual das comunidades de afro-descendentes na sociedade brasileira. A proposta de Cuti, claramente afirmada como proposta de escritor negro, permite-lhe trazer para a "arena” do discurso literário, outros discursos como o religioso e o discurso técnico de instrução. Trata-se, nesta proposta, não apenas de uma tensão entre a adoção de valores hegemônicos diferentes dos valores negros, mas de clara política de desmonte dos primeiros, minando os discursos naturalizados que os sustentam e infiltrando neles valores até então "negados". Trata-se, em última instância, de tornar estranha a base de autoridade de discursos que, com hipocrisia requintada, apagam um problema para o qual os poetas negros se propõem a buscar soluções.

E-mails: pagano@dedalus.lcc.ufmg.br celiamag@dedalus.lcc.ufmg.br 


\section{REFERÊNCIAS BibliográficAS}

BhabHa, Homi. 1994. The Location of Culture. London \& New York: Routledge.

Bнавна, Homi. 1998. O local da cultura. Trad. de Myriam Ávila, Eliana Lourenço de Lima Reis e Gláucia Renate Gonçalves. Belo Horizonte: Editora da UFMG.

Barker, Chris e Dariusz Galasínski. 2001. Cultural studies and discourse analysis: a dialogue on language and identity. London/Thousand Oaks/ New Delhi: Sage Publications.

Campello, Joli. Folia em voz Nagô. http://www.aponte.com.br/carnaval/zoada/zoada-02-02-05.html

Cassell, Philip (Ed.) 1993. The Giddens Reader. Stanford, CA: Stanford University Press.

Cavalcanti, M. 1999. Estudos sobre educação bilíngüe e escolarização em contextos de minorias lingüísticas no Brasil. DELTA,15 Especial: 385-417.

Celani, M.A.A. 1998. Transdisciplinaridade na Lingüística Aplicada no Brasil. In: Inês Signorini e Marilda C. Cavalcanti (Orgs.) Lingüística Aplicada e Transdisciplinaridade. Campinas, SP: Mercado de Letras: 129-142.

Chouliaraki, Lilie \& Norman Fairclough. 1999. Discourse in late modernity. Edinburgh: Edinburgh University Press.

Cutı. 1995. Entrevista com Charles H. Rowell. Callaloo, v. 18. 4 : 901-904.

. 1998. Para ouvir e entender estrela. Cadernos Negros: Os Melhores Poemas. São Paulo: Quilombhoje.

. 2000. Poesia erótica nos Cadernos Negros. In: Fonseca, Maria Nazareth Soares (Org.) Brasil Afro-Brasileiro. Belo Horizonte: Autêntica.

During, Simon (Ed.) 1999. Introduction. In: The Cultural Studies Reader. London e New York: Routledge: 1-28.

Fairclough, N. 1992. Discourse and social change. Cambridge: Polity Press. . N. 2000. Linguistic and Intertextual Analysis within Discourse Analysis. In: Jaworski, Adam \& Nikolas Coupland (Eds.) The Discourse Reader. London \& New York: Routledge.

Hall, Stuart (Ed.) 1997. Representation: Cultural Representations and Signifying Practices. London/Thousand Oaks/New Delhi: Sage. 
Hall, Stuart. 1999. Cultural studies and its theoretical legacies. In: Simon During (Ed.) The cultural studies reader. Second edition. London e New York: Routledge: 97-109.

Halliday, M.A.K. e R. Hasan. 1976. Cohesion in English. London: Longman. Halliday, M.A.K. \& Ruqaya Hasan. 1993. Language, Context, and Text: Aspects of Language in Social-semiotic Perspective. Victoria, Australia: Deakin University Press.

Hoey, Michael. 2001. Textual Interaction: An Introduction to Written Discourse Analysis. London \& New York: Routledge.

Loomba, Ania. 1998. Colonialism/Postcolonialism. London \& New York: Routledge.

Magalhães, Célia M. 2001. Reflexões sobre a análise crítica do discurso. Belo Horizonte, FALE:UFMG.

Magalhães, Izabel. 2000. Eu e Tu: a constituição do sujeito no discurso médico. Brasília: Thesaurus Editora.

Mills, Sara. 1997. Discourse. London \& New York: Routledge.

Morta Lopes, L. P. 1998. A transdisciplinaridade é possível em Lingüística Aplicada? In: Inês Signorini e Marilda C. Cavalcanti (Orgs.) Lingüústica Aplicada e Transdisciplinaridade. Campinas, SP: Mercado de Letras: 113-128.

Pereira, Edmilson de Almeida. 1995. Panorama da literatura afrobrasileira. Callaloo, v. 18. 4: 1035-1040.

Serres, Michel. 1993. Filosofia Mestiça. Trad. Maria Ignez Duque Estrada. Rio de Janeiro, RJ: Editora Nova Fronteira.

Rajagopalan, Kanavillil. 2000. Self-fashioning in and through language: implications for critical discourse analysis. Cadernos de Linguagem e Sociedade, 4: 68-78.

Robinson, Douglas. 1997. Translation and Empire: Poscolonial Theories Explained. Manchester, UK: St. Jerome Publishing.

Simon, Sherry. 1999. Hybridité Culturelle. Montréal: L'Île de la tortue et Sherry Simon.

SpIvaK, G. 1990. Postcoloniality and value. In: P. Collier e Gaya-Ryan (Eds.) Literary Theory Today. Chicago: University of Chicago Press.

Young, Robert J.C. 1990. White Mithologies: Writing History and the West. London \& New York: Routledge. . 1995. Colonial desire: hybridity in theory, culture and race. London e New York: Routledge. 